\title{
Capability of Aspergillus niger to bioconcentrate cesium-137 and cobalt- 60 from medium and low level radioactive waste solution simulates
}

\author{
Hosam Eldin El-Sayyad ${ }^{1, *}$, Samir Basha Eskander ${ }^{2}$, Talat A. Bayuomi ${ }^{3}$ \\ ${ }^{1}$ Lecturer, Middle Eastern Regional Radioisotope Centre for the Arab Countries, (Al-Ghad International College for Applied \\ Medical Sciences), ${ }^{2,3}$ Professor, Dept. of Radioisotope, Egyptian Atomic Energy Authority, Egypt \\ *Corresponding Author: \\ Email: helhalby@gc.edu.sa
}

Received: $28^{\text {th }}$ April, 2018

Accepted: $31^{\text {st }}$ July, 2018

\begin{abstract}
Introduction: The bioremediation, as a treatment process for low- and medium radioactive liquid wastes generated from various applications of nuclear technology in our daily life, represents a biotechnological innovation as well as an excellent tool for bioconcentration of radionuclides.

Aim: study the capability of Aspergillus niger (A. niger) to removal of Cesium-137 (Cs-137) and/or Cobalt - 60 (Co-60) from simulated spiked solutions.

Materials and Methods: This part of experimental work was carried out to evaluate the factors influencing the performance of the fungus and optimizing the bioconcentration of those two radionuclides. The impacts of incubation periods, irradiation of fungus spores prior seeding, age of $A$. niger and the initial concentrations of the radioactivity added on the bioconcentration factor $(\mathrm{CF})$ for the two radioions were studied on laboratory scale experiments.

Results and Discussion: Based on the data reached it was found that A. niger can bioconcentrate, from the spiked solution, more than $80 \%$ of Co-60 and about $25 \%$ of Cs- 137 within 48 hours.

Conclusion: Therefore, Aspergillus niger can be easily grown in substantial manner using unsophisticated techniques, inexpensive growth media. Besides, the acceptable bioconcentration factor achieved by the fungi constituted an economical pattern for treating hazardous effluents spiked with radioactive ions, and it might have a synergetic role during applying other treatment methods.
\end{abstract}

Keywords: Aspergillus niger, Bioconcentration factor, Co-60, Cs-137.

\section{Introduction}

Gamma emitting radionuclides, e.g. Cesium -137 and Cobalt-60, are the main contributors to the dose rate provided by the regular radioactive wastes from the nuclear installations. The main objective for managing and disposing of radioactive wastes is to protect people and the environment. This means isolating or treating these wastes so that the rate or concentration of any radionuclides contained and returned to the biosphere are harmless. ${ }^{1}$ Nuclear wastes are neither particularly hazardous nor hard to manage relative to other toxic industrial wastes. Treatment of aqueous radioactive waste quite often involves the application of several treatment techniques such as filtration, precipitation, sorption, evaporation and/or membrane separation, ${ }^{2}$ ion exchange, ${ }^{3}$ evaporation, ${ }^{4}$ acid digestion and wet oxidation. $^{5}$

In addition to those widely used methods, environmentally friendly processes had been experienced in the last decades and including biosorption, $^{6-8} \quad$ phytoremediation ${ }^{9-11}$ and bioremediation. ${ }^{6}$ Bioconcentration is a process of a bioremediation concept for hazard radionuclides by utilizing some natural biological sources including bacteria, fungi, yeast, algae, etc. The advantage of bioremediation is not only to be functioned under a broad spectrum of conditions like $\mathrm{pH}$, temperature etc., but also to be found as environment friendly technique and economically feasible due to the cheap raw supplies that can be utilized as bioconcentrator. ${ }^{12}$ The efficiency of thorium biosorption by A. niger was studied by Christopher and Gadd. ${ }^{13}$ A. niger shows simultaneous accumulation of $\mathrm{Co}$ (II) and $\mathrm{Eu}$ (III) from waste water. ${ }^{14}$ Eupenicillium sp., Penicillium oxalicum and Aspergillus niger showed the most effective radionuclide ${ }^{242} \mathrm{Pu}$ sorption. ${ }^{15}$ Both ${ }^{60} \mathrm{Co}$ and ${ }^{137} \mathrm{Cs}$ were also removed by Aspergillus pulverulens. ${ }^{16}$

In the present study, bioaccumulation efficiency of Aspergillus niger towards the two gamma emitters, namely Cs-137 and Co-60, from spiked simulated aqueous solutions was evaluated by characterizing and computed bioconcentration factor for the two radionuclides under various experimental conditions e.g. incubation period, irradiation of fungal spores, age of fungus and initial radioactivity contents added.

\section{Materials and Methods}

Isolation of Micro-Organisms from Radioactive Waste Simulates: The main aim of the present study was to evaluate the synergetic role, the tolerance and the bioaccumulation potential of $A$. niger fungal strain toward radiocesium and radiocobalt spiked solutions. The fungi were isolated from radioactive waste stream subjected to pre- treatment sorption step using Camellia sinensis leaf. ${ }^{8}$ Post the sorption process, a radioactive waste solution containing1 $\mathrm{gm}$ of the dried spent black 
tea leaves (dregs) was incubated for three days at $25^{\circ} \mathrm{C}$. After this incubation period, the developed colonies were picked and isolated onto Sabouraud Dextrose agar (SDA) media (peptone-preferably mycological, 1\%, Dextrose $4 \%$, agar $1.5 \%, \mathrm{pH} 5.6$ ) one of the recommended media for fungal growth. To ensure the growth of micro-organisms present in samples, three replicates were prepared. The results obtained affirmed that the three media were very close. Purified isolate of fungus was obtained by streaking repeatedly colonies in SDA medium and examined using a light microscope.

Identification of Fungi: The fungal cultures were identified on the basis of macroscopic (colonial morphology, color, texture, shape, diameter and appearance of colony) and microscopic (septation in mycelium, presence of specific reproductive structures, shape and structure of conidia, and presence of sterile mycelium) characteristics. ${ }^{17}$ Pure cultures of isolated micro-organisms were identified using the keys of Domsch et al. ${ }^{18}$ and Barnett \& Hunter. ${ }^{19}$
The data obtained from macroscopic (Fig. 1 a \& b) and microscopic (Fig. $1 \mathrm{c} \& \mathrm{~d}$ ) examinations confirmed that Aspergillus niger is the isolated fungal strain.

Maintenance of the Microorganism: The experimental culture was the descendant from single slants of the pure organism, and was maintained on agar slants of modified Dox's medium.

A sufficient quantity of spores was extracted from mature A. niger cultures. This was accomplished by spatula down on sterile Petri dishes. Spores were then pushed on sterile saline $(0.85 \% \mathrm{NaCl})$, and were diluted into a suspension of $\approx 10^{6} \mathrm{spore} / \mathrm{ml}$ in a sterile beaker.

Simulated Radioactive Waste Solutions: Simulated waste solutions were prepared by adding predetermined contents of a carrier free radiocesium (Cs-137, T1/2= 30.5 years) and radiocobalt (Co-60, T1 $12=5.25$ years) to tap water. The two radionuclides were purchased from Radioisotope Center Polatom Institute of Atomic Energy, Poland as cesium and cobalt chloride solutions.

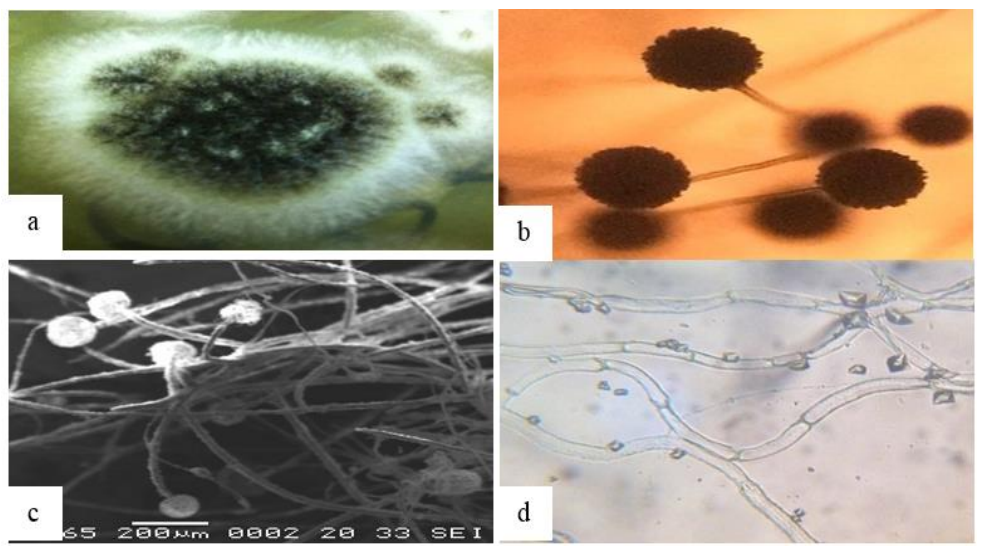

Fig. 1: Macroscopic and microscopic examination of the isolated $A$. niger

Bioconcentration of Radioactive Pollutants: A known volume of the simulated radioactive waste solution i.e. with predetermined specific activity $(\mathrm{Bq} / \mathrm{ml})$, was added to flask containing $100 \mathrm{ml}$ sterile Sabouraud Dextrose broth (SDB), then seeded with constant inoculum of pure isolated fungal strain. At marked incubation periods, under ambient conditions, an aliquot from the culture solution was withdrawn for analysis. The collected samples were radiometrically analyzed using 3"x3" well type NaI crystal (efficiency $85 \%$ ) based on Multi- Channel Analyzer PCA-P, USA. The bioconcentration factor $(\mathrm{CF})$ and bioremoval percentage for the radioactivity were calculated according to following relations:

Bioconcentration Factor $(\mathrm{CF})=\frac{\text { radioactivity retained by } \text { A. } \text { niger fungi in } \mathrm{Bq}}{\text { total radioactivity remained in solution in } \mathrm{Bq}}$

Bioremoval percent $=\frac{\mathrm{Ao}-\mathrm{At}}{\mathrm{At}} * 100$

Where:

$\mathrm{Ao}=$ the initial activity added in $\mathrm{Bq}$.

$\mathrm{At}=$ the remaining activity in treated solution in $\mathrm{Bq}$.

Effect of Incubation Period: One $\mathrm{ml}$ of A. niger spore suspension was inculcated into Erlenmeyer flask (250 $\mathrm{ml}$ cap.) containing $100 \mathrm{ml}$ sterile SDB spiked with computed activities of Cs- 137 and Co- 60. The

behaviour of the two radionuclides was followed over 190 days at $28 \pm 2^{\circ} \mathrm{C}$. Equal aliquots of the clear solution were collected at definite periods and counted for their radioactivity contents.

Effect of Gamma Irradiation of Fungal Spores on Radionuclides Bioconcentration Process: The spore suspensions of $A$. niger were distributed in sterile Eppendorf's tubes $(1.5 \mathrm{ml}$ in each). One group was 
subjected to 200 Gray (Gy) gamma irradiation dose using a Cobalt-60 gamma cell source located at the National Centre for Radiation Research and Technology - Atomic Energy Authority, Nasr City, Cairo at $13.3 \mathrm{~Gy} / \mathrm{min}$ dose rate during the irradiation time. Similar Eppendorf's tube was used as a control i.e. containing non irradiated $A$. niger spores. The bioconcentration factors were determined by inculcation separately one $\mathrm{ml}$ of the irradiated and the non-irradiated fungal spore suspensions into a sterile $250 \mathrm{ml}$ conical flask, each containing $100 \mathrm{ml}$ of SDB spiked with Cs- 137 and Co -60 mixtures. The two flasks were left at ambient conditions $\left(28 \pm 2^{\circ} \mathrm{C}\right)$ for 190 days. An aliquot of the supernal solution was collected from each culture medium at precise periods and analyzed radiometrically.

Effect of Increasing Radioactivity Contents added on Bioconcentration Factor: To five Erlenmeyer flasks (250 ml cap.), each containing $100 \mathrm{ml}$ sterile Sabouraud Dextrose liquid medium, solutions with increasing radioactivity of both radiocesium and radiocobalt (Table 1), were added.

Table 1: Total radioactivity added in Becquerel (Bq)

\begin{tabular}{|l|c|}
\hline Sample number & $\begin{array}{c}\text { Total radioactivity } \\
\text { added*, Bq }\end{array}$ \\
\hline I & 2475 \\
\hline II & 9507 \\
\hline III & 14261 \\
\hline IV & 19014 \\
\hline V & 33182 \\
\hline
\end{tabular}

The spiked media were inoculated each with $1 \mathrm{ml}$ of spore suspension $\left(\approx 10^{6}\right.$ spores $\left./ \mathrm{ml}\right)$ of the fungi and then left at room temperature $\left(28 \pm 2^{\circ} \mathrm{C}\right)$. One $\mathrm{ml}$ of the clear culture solution was collected each time periodically for 190 days and analyzed radiometrically. Effect of Age of Fungal Spores on the Radionuclides Uptake: To study the impact of the age of $A$. niger spores on its bioconcentration performance for radiocesium and/or radiocobalt, one $\mathrm{ml}$ of fungal spore suspension was inoculated separately into three flasks each containing $100 \mathrm{ml}$ of Sabouraud dextrose liquid media. Each flask was spiked with equal definite radioactive contents either directly or after three, four and eight days post inculcation of fungal spores. The flasks were left at $28 \pm 2^{\circ} \mathrm{C}$ for 190 days. One $\mathrm{ml}$ of the clear culture solution was collected out of each flask at dependable time and counted for the remained radioactivity.

\section{Results and Discussion}

As previously explained, radio-resistant $A$. niger was isolated from pre-treated radioactive waste solution simulate and applied for new bioconcentration process of radiocesium and /or radiocobalt from their fresh spiked solutions to evaluate the task of microorganisms treatment process.

Based on the present experimental work and data from the literature, it is worth to notify that, all the bioremoval and bio-concentration curves reached followed nearly the same pattern. Fluctuations in behavior, where, periodic 'ups and down' cycles discern.

The first period showed a rapid initial bioremoval of the radioactivity, followed by drop wise decline in the removal percentage. Those cycles were repeated along the whole experimental period Graph 1).

\section{Graph 1: The Bioremoval percentage of total Cs-137\&Co-60 radioactive pollutants as function of} incubation time

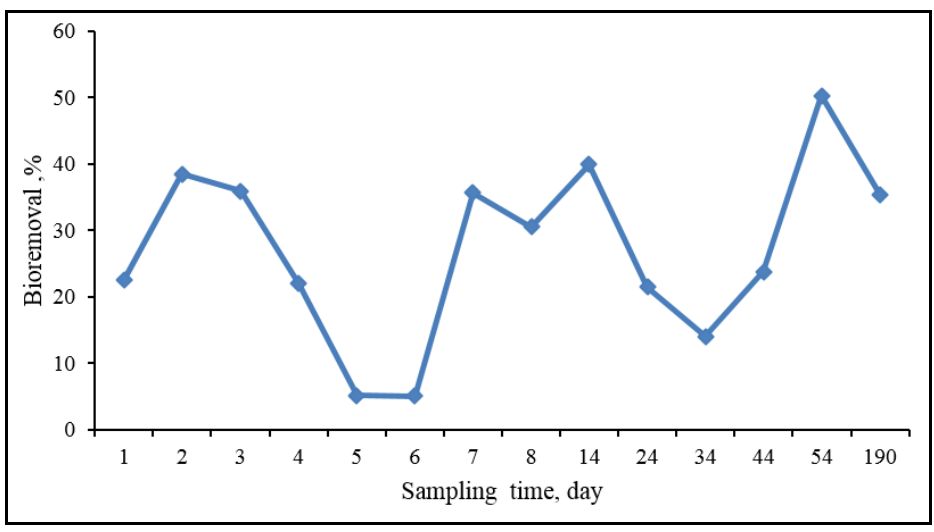

Aspergillus niger showed bioremoval percentages (BP) of $38.5,35.7,39.9,50.3$ and $35.5 \%$ of the total radioactivity added (Cs-137 \& Co-60) after 2, 7, 14, 54, and at 190 days, respectively. A little uptake was observed at lag periods or the early stage of growth (up to the first day). This can be explained on the basis that the fungal growth starts slowly, viable spores begin swelling which happened before their germination, then the growth rate accelerates gradually. ${ }^{20}$ 
The maximum radioactive nuclides bioremoval percentages took place during the exponential phases. This may be attributed to initiation of the hyphae branching, and extending new hyphae at a linear rate into un-colonized regions of substrate. The biomass of the growing fungus duplicated itself per unit time. As long as the nutrients in the medium are in excess, the growth of the microorganisms remains proceeding. A retarding period, where the bio-removal percentage begins to decline to reach $\approx 5 \%$ after the fourth day up to nearly the seventh day of incubation. This is supposed to be due to that the fungal mycelia were eventually died off. The death process is usually accompanied by their breakdown through self-digestion and, hence, the radioactive materials might be released again to the medium.

In addition, this behavior may be referred to the changes in cell-wall composition as a result of the accumulated $\gamma$ - irradiation dose effect of both Cs-137 (peak energy at $0.662 \mathrm{MeV}$ ) and Co-60 (two peaks energy at $1.17 \&$ at $1.33 \mathrm{MeV}$ ) which accompanied with the release of metabolites that were bound, already, to the radio- ion. However it is reported that, both living and dead microorganisms possess abundant functional groups on their cell surfaces that bind metal ions. ${ }^{21} \mathrm{At}$ the end of this phase, A. niger form spores by fragmentation of the hyphae and began a new bioconcentration process of radioactive pollutants through the newly formed hyphae and repeated the growth pattern throughout the 190 days incubation period (Graph 1). This also, reflects the acceptable tolerance performance of fungi towards the highly surrounding $\gamma$-irradiation environment.
In relation to recovery, it was observed that Aspergillus niger lost small part of its biosorption capacity after the first cycle and was able to maintain the rest of its capacity for two more cycles. Therefore, it is recommended to harvest the spiked fungi after 3 days and re-inoculate fresh spores for a new treatment cycle till an appropriate solution free of radiocontaminants is reached.

Impact of Gamma Irradiated Fungal Spores on the Bioconcentration of Cs-137 and Co-60 Radionuclides: It was reported that low doses of gamma irradiation produce stimulatory metabolic effects in fungi. It causes increase in total protein in Alternaria tenuissima, Botrytis cinerea, Penicillium expansum and Stemphylium botryosum. ${ }^{22}$ It is suggested that protein might play an important part in protection against the harmful effect of radiation. Significant improvement in production of $\alpha$ - and $\beta$ galactosidases enzymes by $A$. niger was reported. ${ }^{23}$

The authors tried the possibility to utilize gamma irradiation treatment of the fungal spores prior their seeding aiming at enhancement of the bioremediation capabilities of A. niger. Graph 2 described the performance of the A. niger post exposing their spores to 200 Gy single dose gamma irradiation and before their inoculation in Sabouraud dextrose liquid media spiked with both radiocesium and radiocobalt.

It is clear that exposing the fungal spores to gamma irradiation stimulated the uptake of radionuclides compare to the not - irradiated ones especially at the late incubation periods.

\section{Graph 2: Effect of irradiated and non-irradiated fungal spores on the bioconcentration factor of total activity from simulated spiked solution}

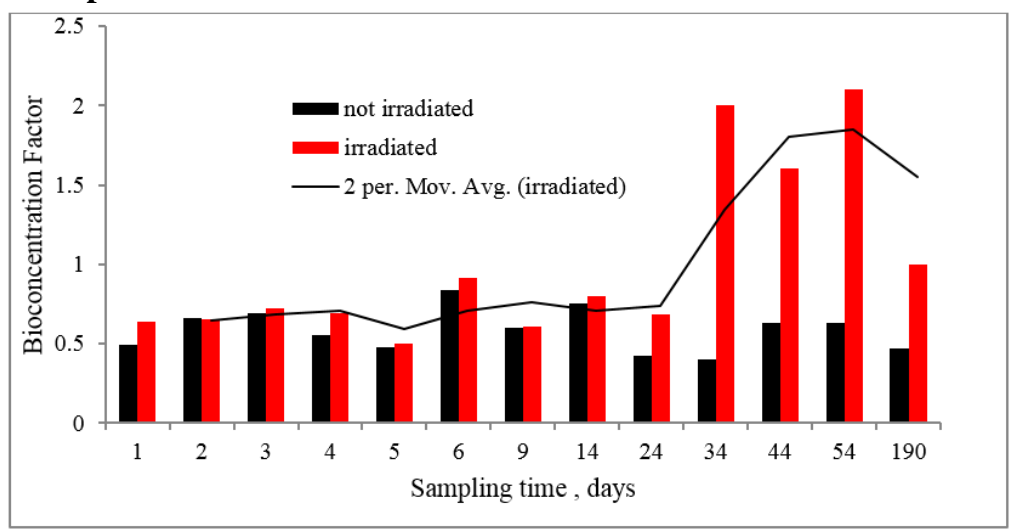

His can be attributed to that; the low gamma irradiation dose stimulated the spore germination and mycelia growth of fungi. The irradiation of A. niger's spores with $200 \mathrm{~Gy}$ dose increase the spore germination and enhance the mycelial growth. ${ }^{24}$ Also, the low doses of gamma irradiation stimulated the germination and germ length of some fungi without losing the fungistatic activity. ${ }^{25}$

The Bioconcentration Factors as Function of the Fungal Spores Age: The age of the microorganism affected negatively the bioconcentration of both Co-60 and Cs-137 from the simulated spiked solution. The CFs for both radionuclides were usually higher for fungi inoculated directly to the solutions compared to that left for pair of days before their inoculation (Graph 3). 
Graph 3: The impact of the age of fungi on the bioconcentration factor of total activity from simulated spiked solution

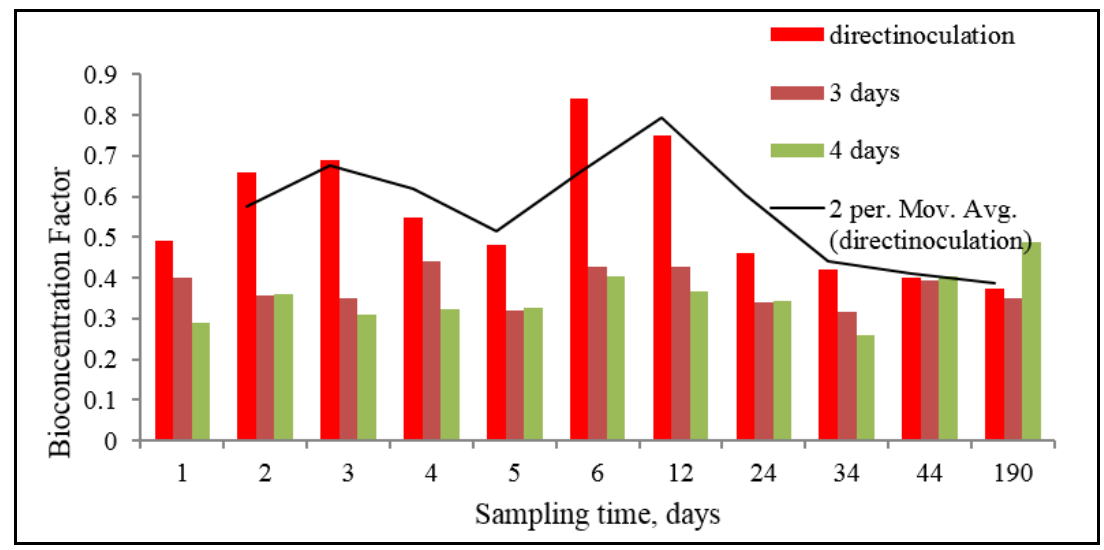

This is possibly due to the presence of many highly active enzymes at this growth phase, during which cells are at their most metabolically active stage. ${ }^{26}$ The maximum heavy metal uptake by some bacterial strains, might occur after three days of incubation. ${ }^{27}$

The Bioconcentration Capability of $A$. niger as Function of Initial Radioactivity Added: Strong radiation resistant microorganisms are considered the first aspect that must be taken into account when bioremediation process for radioactive contamination is decided to be followed.

From the Graph 4, during the whole 190 days incubation period, it is clear that the highest bioconcentration factors for radiocesium was corresponding to the largest radioactivity added i.e. $9517 \mathrm{~Bq}$ of Cs-137.

\section{Graph 4: The bioconcentration factor for Cs-137 as a function of initial radioactivity added}

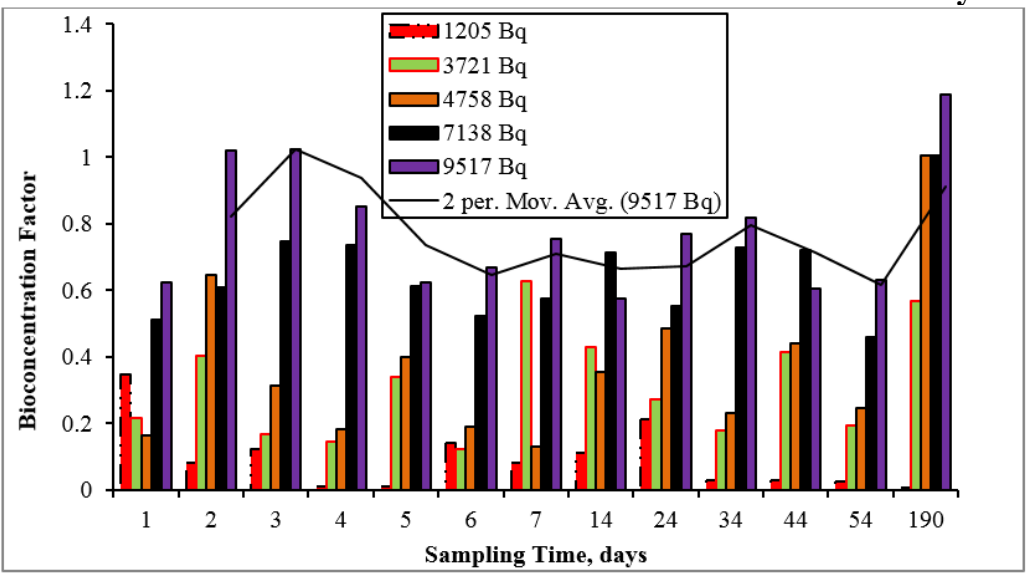

This followed by CFs at 7138, 4758 and $3721 \mathrm{~Bq}$, respectively, during the same incubation period. On the other hand, the minimum CFs were obtained for Cs- 137 activity at $1205 \mathrm{~Bq}$. Identical fluctuated trends for the bioaccumulation of radionuclides throughout the incubation period were relayed (Graph 4).Close conclusions for cold Cs were published by Seeprasert \& Yoneda $^{28}$ and Volesky, ${ }^{29}$ where, the amount of Cs adsorbed by fungi increased indefinitely and proportionally to the Cs concentration in the solution.

Bearing in mind that, the fate of $\mathrm{Cs}$ in the environment is primarily influenced, in general, by sorption process,$^{30}$ as previously reported and according to Dadachova et al., ${ }^{31}$ increased biomass of some fungal strains isolated from areas having higher radiation level. Therefore, it is assumed, at the highest initial radioactivity value added, extensive biomass of $A$. niger would be found and consequently more active sites for Cs-137 sorption could exist. Furthermore, according to Dighton et al. ${ }^{32}$ the hyphal extension rates are enhanced in fungi isolated from radioactively contaminated areas. 


\section{Graph 5: The bioconcentration factor for $\mathrm{Co-60}$ as a function of initial radioactivity added}

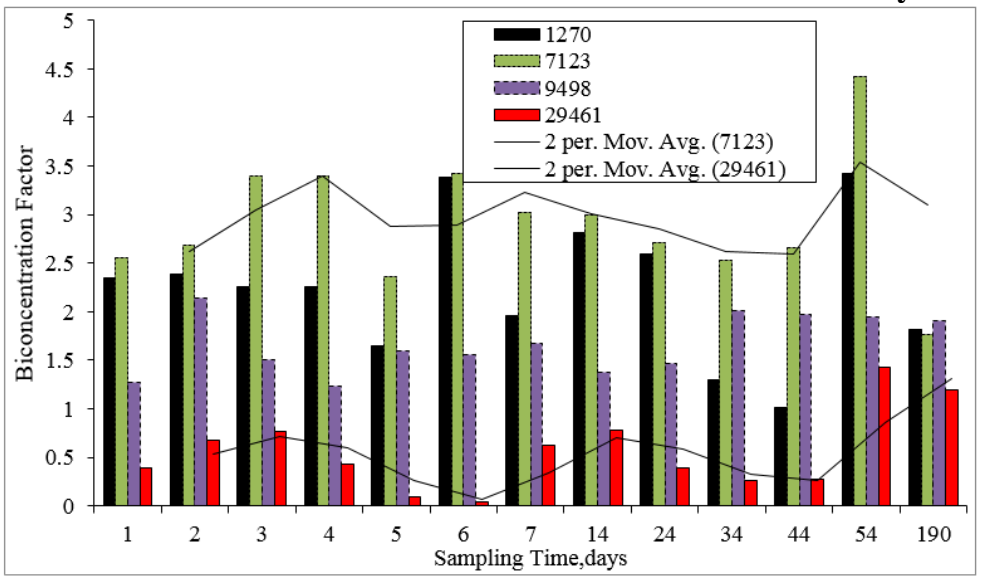

It is clear from Graph 5 that directional bioconcentration factors for Co-60 were maximal at moderate and low radioactivity contents, i.e. at 71.23 and $12.7 \mathrm{~Bq} / \mathrm{ml}$. On the other hand, the CFs were lowest at the highest levels i.e. 294.61 and $94.98 \mathrm{~Bq} / \mathrm{ml}$, respectively. This can be explained on the basis that the bioconcentration of radiocobalt is, mainly, metabolic dependant process. Hence at low and moderate activity contents, enhancement in the biological activities assumed to be happened. While high doses of gamma irradiation can cause dose-dependent inhibitory effects in fungi. ${ }^{33}$
However, it should be reported that the fungi are still alive even after this long period of incubation (190 days).

The results represented in Tables 2 \& 3 demonstrated that $A$. niger which was the most abundant fungus isolated from radioactive waste environment showed more tolerance for gamma irradiation. This can be due to physiological adaptation of the microorganism, ${ }^{34}$ and could be associated with increased tolerance for gamma irradiation and may be attributed to the melanin layer, (Fig. 2), adhering to the conidial cell wall of A. niger. ${ }^{35}$

Table 2: The calculated total accumulated dose due to Co-60 after 190 days at contact to fungus as function of activity content added

\begin{tabular}{|c|c|c|}
\hline Activity added (mean values), Bq & Dose rate, ${ }^{*} \boldsymbol{\mu S} /$ hour & Total Dose, $\boldsymbol{\mu S}$ \\
\hline 1270 & $3.9 \mathrm{E}+007$ & $1.8 \mathrm{E}+0011$ \\
\hline 7123 & $2.2 \mathrm{E}+0010$ & $1.0 \mathrm{E}+0014$ \\
\hline 9497 & $2.9 \mathrm{E}+0010$ & $1.3 \mathrm{E}+0014$ \\
\hline 29461 & $9.1 \mathrm{E}+0010$ & $4.2 \mathrm{E}+0014$ \\
\hline
\end{tabular}

* calculated based on Rad Pro

Calculator.src="http://c40.statcounter.com/3546775/0/eb02ab58/1/"

Table 3: The calculated total accumulated dose due to Cs-137 after 190 days at contact to fungus as function of activity content

\begin{tabular}{|c|c|c|}
\hline Activity added (mean values), Bq & Dose rate, ${ }^{*} \boldsymbol{\mu S} /$ hour & Total Dose, $\boldsymbol{\mu S}$ \\
\hline 1205 & $9.2 \mathrm{E}+006$ & $4.2 \mathrm{E}+0010$ \\
\hline 3721 & $2.8 \mathrm{E}+007$ & $1.3 \mathrm{E}+0011$ \\
\hline 4758 & $3.6 \mathrm{E}+007$ & $1.6 \mathrm{E}+0011$ \\
\hline 7138 & $5.5 \mathrm{E}+007$ & $2.5 \mathrm{E}+0011$ \\
\hline
\end{tabular}

* calculated based on Rad Pro Calculator src="http://c40.statcounter.com/3546775/0/eb02ab58/1/"

There is a postulation that the fungal hyphae are able to use the energy for metabolism. ${ }^{31}$ Melanin or other natural quinine pigments in the fungal cell wall may act as the radiation receptor for this response.
Melanin has the capacity to change the biochemical pathways in fungal cells when exposed to radiation. ${ }^{31,36-}$ 40 


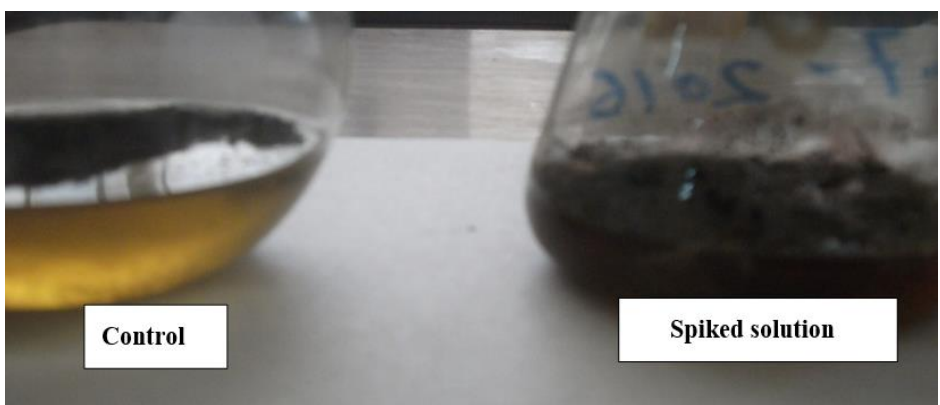

Fig. 2: Melanin formed in the spiked solution with Cs-137 \& Co-60 compared to the control unspiked one post 190 days incubation period

\section{Conclusion}

Based on the experimental results, it can be concluded that $A$. niger can be harnessed as bioconcentration agent for Cs-137 and Co-60 radionuclides from the contaminated solution simulates. About $80 \%$ of Co- 60 and about $25 \%$ of Cs- 137 were removed from the simulated spiked solution by the second day post inoculation. Besides, the microorganism might have a synergetic role during application of other treatment methods. The present study can be a step for further assessment and management of natural bio sorbent (fungus) which could serve as an economical material for treating low and intermediate level radioactive effluents originated from the peaceful applications of nuclear technology in the daily life.

\section{References}

1. Radioactive Waste Management. "World Nuclear Association website, e: info@world-nuclear.org .radionuclides emitted by in the Chernobyl accident" Mycol. Res. (2016).

2. Dulama MN, Deneanu M, Pavelescu LP. Combined Radioactive Liquid Waste Treatment Processes Involving Inorganic Sorbents and Micro/Ultrafiltration. Rom Journ Phys., 2009;54:851-859.

3. Gangadharan A, Jasu NS, Benny WG, Tomar NS, Kaushik CP, Singh KM, Wattal PK. Management of intermediate level radioactive liquid waste (ILW) at WIP, Trombay. Technology Development Article BARC NEWSLETTER(2013) 70 ISSUE, NO. 335.

4. International Atomic Energy Agency. Handling and processing of radioactive waste from nuclear applications. TRS. (2001) No. 402; IAEA: Vienna, Austria.

5. Ghattas NK, Eskander SB. New technology for the treatment of low and intermediate level radioactive organic waste from nuclear applications. Final report of a co-ordinated research programme 1991-1996. Treatment Technologies for Low and Intermediate Level Waste from Nuclear Applications IAEA-TECDOC-929(1997) 65, IAEA, Vienna.

6. Eskander SB, Khalil LH, Sabry DY, Mostafa K H M. "Ion Exchange Characteristic of Caboxymethylated Cross Linked Pregelled Starch. Removal of 6oCo and 137Cs from Aqueous Waste Solution "Proceeding of the Seventh conference of Nuclear Science and Applications (2000)1, 473-481.

7. Tawfik ME, Eskander SB, Elsabee MZ. "Extracted Chitosan as Biosorbent for 60Co and 137Cs from
Radioactive Waste Simulates.” Elastomers and Plastics, KGK. 2015;3:30-36.

8. Eskander SB, Bayuomi TA. Biosorption of ${ }^{137} \mathrm{Cs}$ and/or ${ }^{60}$ Co from Radioactive Waste Solution Simulates Using Spent Black Tea (Camellia sinensis) Dregs. International Journal of Materials Chemistry and Physics. 2015;1(3):333-342

9. Hamdy KH. "Treatment and Conditioning of Hazardous and Radioactive Wastes" M.Sc. thesis (2012) Faculty of Science, Cairo University, Cairo, Egypt. 148-163.

10. Eskander SB, Nour El-dien FA, Hoballa EM, Hamdy KH Capability of LemnaGibba to Biosorb Cesium-137 and Cobalt-60 from Simulated Hazardous Radioactive Waste Solution. Journal of Microbiology, Biotechnology and Food Science. 2011a;2: 148-163.

11. Kamel HA, Eskander SB, Aly MAS. Physiological response of Epipremnumaureum for cobalt-60 and cesium-137 translocation and rhizofiltration.

International Journal of Phytoremrdiation. 2007;9:403417.

12. Shazia I, UzmaSadia GR, Talat A. Bioremediation of Heavy Metals Using Isolates of Filamentous Fungus Aspergillusfumigatus Collected from Polluted Soil of Kasur, Pakistan. International Research Journal of Biological Sciences. 2013;2(12):66-73.

13. Christopher W, Gadd GM. Biosorption of Radionuclides by Fungal Biomass. Journal of Chemical technology and biotechnology. 1990;49(4):331-343.

14. Wencheng S, Jun L, Tao W, Xiangxue W, Jun H, Tasawar H, Ahmed A, Xiangke W. Accumulation of $\mathrm{Co}(\mathrm{II})$ and $\mathrm{Eu}(\mathrm{III})$ by the mycelia of Aspergillusniger isolated from radionuclide-contaminated soils. Chemical Engineering Journal. 2016;304,186-193.

15. Alexey L, BenediktaL, Rūta D, Vidmantas R, Dalis B. "Pu (IV) and Fe (III) accumulation ability of heavy metal-tolerant soil fungi" NUKLEONIKA. 2009;54(4):285-290.

16. Mahmoud YAG. Uptake of radionuclides by some fungi. Mycobiology. 2004;32:110-114.

17. Zafar S, Aqil F, Ahmad I. Metal tolerance and biosorption potential of filamentous fungi isolated from metal contaminated agricultural soil. Bores Technol. 2006;98:2557-61.

18. Domsch KH, Gams W, Anderson TH. "Compendium of soil fungi”. London, England: Academic Press (1980).

19. Barnett HL, Hunter B, B "Illustrated genera of imperfect fungi”, 2nd Edn. Burgess Publishing, Minneapolis (1998) MN. p. 218.

20. Mesquita BB, Alastair S, Randolph MS, James DM. "The Logic of Political Survival". Cambridge (2003) The MIT Press.

21. McLean RJC, Fortin D, \& Brown DA. "Microbial metalbinding mechanisms and their relation to nuclear waste disposal. J Microbiol. 1996;42,392-400. 
22. Geweely S, Nawar, LS. Sensitivity to gamma irradiation of post-harvest pathogens of pear. Int J Agric Biol, 2006;8(6):710-716.

23. Awan MS, Tabbasam N, Ayub N, Babar ME, Rahaman M, Rana SM, Rajoka MI. Gamma radiation induced mutagenesis in Aspergillus niger to enhance its microbial fermentation activity for enzyme production. Mol Biol Rep. 2011;38(2):1367-1374.

24. Abd-El-Salam A, El-Sayyad H. "Studies of Gamma Irradiation on the Growth and the Bioconversion of Progesterone Using Aspergillus niger. 100ISOTOPE \& RAD RES. 2010;42(4)(Suppl.1):1321-1329.

25. El-Abyad MSH, Ismaila K. Germination of non-irradiated and gamma-irradiated fungal spores on water agar and natural soil. ZblBaktHyg. 1979;134:681-687.

26. Kumar A, Bight BS, Joshi VD. "Biosorption of Heavy Metals by four acclimated microbial species, Bacillus spp., Pseudomonas spp., Staphylococcus spp. And Aspergillusniger. J. BIOL ENVIRON SCI. 2010;4(12):97108.

27. Mondal P, Maumder CB, Mohanty B. "Treatment of arsenic contaminated water in a laboratory scale up flow bio-column reactor". J Hazard Material. 2003;153(12):126-145.

28. Seeprasert P, Yoneda M, "Shimada Y, Matsui Y. The Sorption of Cesium on Fungi Cell. International Journal of Pharma Medicine and Biological Sciences. 2016;4:110-115.

29. Volesky B. Removal and recovery of heavy metals by biosorption. In Biosorption of heavy Metals; CRC Press: Boca Raton, FL, (1990); pp 7-44.

30. Siddiquee S, Rovina K, Azad SA, Naher L, Suryani S, Chaikaewl P. Heavy Metal Contaminants Removal from Wastewater Using the Potential Filamentous Fungi Biomass. J Microb Biochem Technol. 2015;7:384-393.

31. Dadachova E, Bryan RA, Huang X, Moadel T, Schweitzer AD, Aisen P, Nosanchuk JD, Casadevall A. Ionizing Radiation Changes the Electronic Properties of Melanin and Enhances the Growth of Melanized Fungi. PLoS. 2007:2:e457.

32. Dighton J, Tugay T, Zhdanova N. Fungi and ionizing radiation from radionuclides. FEMS Microbiol Lett. 2008;281:109-120.
33. Maity JP, Kar S, Banerjee S, Chakraborty A, SantraSC. "Effects of gamma irradiation on long storage seeds of Oryza sativa (cv.2233) and their surface infecting fungal diversity. Radiat Phys Chem., 2009:8(11):1006-1010.

34. Butler M J, Day A W. Fungal melanin's. J. Microbiol. 1998;(44)12:1115-1136.

35. Gadd GM. "Interaction of fungi with toxic metals. New Phytol. 1993;124(1):25-60.

36. Durrell LW, Shields LA. "Fungi isolated in culture from soils of the Nevada test Site. Mycologia. 1960;52:636641.

37. Zhdanova NN, Vasilevskaya AI, Artyshkova LV, Sadovnikov YS, Gavrilyuk VI, Dighton J. Changes in the micromycete communities in soil in response to pollution by long-lived radionuclides emitted by in the Chernobyl accident. Mycol Res. 1995;98:789-795.

38. Huselton CA, Hill HZ. Melanin photosensitizes ultraviolet light (UVC) DNA damage in pigmented cells. Environ Molec. Mutagenesis. 1990;16:37-43.

39. Gauslaa Y, Solhaug KA. Fungal melanins as a sun screen for symbiotic green algae in the lichen

Lobariapulmonaria, Oecologia. 2001;126:462-471.

40. Tugay T, Zhdanova NN, Zheltonozhsky V, Sadovnikov L. Dighton J. The influence of ionizing radiation on spore germination and emergent hyphal growth response reactions of microfungi. Mycologia. 2006 b;98(4):521527.

How to cite this article: El-Sayyad HE, Eskander SB, Bayuomi TA. Capability of Aspergillus niger to bioconcentrate cesium-137 and cobalt- 60 from medium and low level radioactive waste solution simulates. Indian $\mathbf{J}$ Microbiol Res. 2018;5(3):318-325. 